\title{
Erratum to: Trade and Flags, the EU's Relations with North East Asia
}

\author{
Michael Reilly
}

\section{Erratum to:}

Chapter 2 in : M. Reilly, Towards an EU-Taiwan Investment Agreement

https://doi.org/10.1007/978-3-319-68403-1_2

The legends of Figure 2.1 have been updated as:

Top left of key (dark green/teal) = China, P.R.: Mainland France Top right of key (light green $)=$ China, P.R.: Mainland Germany Bottom left of key (orange) = China, P.R.: Mainland Italy Bottom right of key (blue) $=$ China, P.R.: Mainland UK

The updated original online version for this chapter can be found at https://doi.org/10.1007/978-3-319-68403-1_2 